\title{
Tumor Identifier Method
}

National Cancer Institute

\section{Source}

National Cancer Institute. Tumor Identifier Method. NCI Thesaurus. Code C117438.

The technique used to administer the tumor identification assessment. 